\title{
Annual, sexual, size- and condition-related variation in the colour and fluorescent pigment content of yellow crest-feathers in Snares Penguins (Eudyptes robustus)
}

\author{
Kevin J. McGraw ${ }^{\mathrm{A}, \mathrm{D}}$, Melanie Massaro ${ }^{\mathrm{B}, \mathrm{C}}$, Trevor J. Rivers $^{\mathrm{A}}$ and Thomas Mattern ${ }^{\mathrm{B}}$

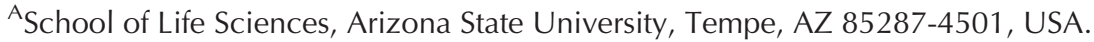 \\ ${ }^{B}$ Department of Zoology, University of Otago, PO Box 56, Dunedin, New Zealand. \\ CPresent address: School of Biological Sciences, University of Canterbury, Private Bag 4800, \\ Christchurch, New Zealand. \\ DCorresponding author. Email: kevin.mcgraw@asu.edu
}

\begin{abstract}
Colourful plumages observed in many birds provide ideal systems for investigating the control and function of animal signals, because we can identify the molecular currency (e.g. pigments, tissue structures) and thus the challenges associated with the production of the trait. To date, most attention has been paid to the signalling costs and benefits of the common pigmentary (e.g. carotenoid- and melanin-based) plumage colours. However, in penguins, the colour of feathers of crests or patches of head plumage is based on an unusual fluorescent pigment, presently thought to be in the class of pterin pigments, which are typically found as colourants in other animals like butterflies and amphibians. These yellow-orange colours may be used in sexual or social communication, but to date little is known about the signalling potential of such ornaments. We collected yellow crest-feathers from adult male and female Snares Penguins (Eudyptes robustus) in two years (2002 and 2003) and examined differences in colour and pigment content as a function of year, sex, body size and body condition. Unlike the typical pattern of birds, crests of female Snares Penguins contained higher concentrations of pigments than those of males. In both years, yellower feathers in females contained more yellow pigment. Birds of both sexes grew yellower and more pigment-rich feathers in 2002 - a year in which birds were in better condition - than in 2003. Males with yellower crests also tended to be larger, heavier and in better condition, regardless of year. These results highlight the potential for yellow crests in Snares Penguins to serve as a condition-dependent indicator to conspecifics. Further work is needed to determine whether or not this plumage trait is a signal of social status or attractiveness, as colourful plumage patches appear to be in other penguin species.
\end{abstract}

\section{Introduction}

Over the past 20 years, understanding the control, function and evolution of sexually selected traits in animals has become a central research thrust among behavioural ecologists (Andersson 1994). Among the more popular sexually selected traits to study have been the brilliant colours of birds, whose origins and mechanisms are now well established (e.g. pigments, tissue structures) and thus provide ideal systems in which to investigate the information communicated by particular signals (Hill and McGraw 2006a, 2006b). It is perhaps not surprising that most attention has been paid to the most colourful and diverse group of birds - the songbirds (Passeriformes). However, species from many other avian orders display brilliant colours, and more research on these groups (e.g. O'Donald 1980; Masello and Quillfeldt 2003; Parker and Ligon 2003) is needed to broaden our understanding of extravagant colouration in birds and animals generally.

Penguins (Sphenisciformes) are often thought of as a uniformly achromatically coloured group, with contrasting black-and-white body plumage. However, more than half of the world's 17 species of penguin display some form of yellow, orange or red colouration in their plumage or bare parts (e.g. bill, legs). For example, King (Aptenodytes patagonicus) and Emperor Penguins (A. forsteri) display yellow to yellowish orange feathers as auricular and breastpatches. Moreover, Yellow-eyed Penguins (Megadyptes antipodes) and all of the 'crested penguins' (Eudyptes), including Rockhopper (E. chrysocome), Macaroni (E. chrysolophus), Fiordland (E. pachyrhynchus), Snares (E. robustus) and Erect-crested (E. sclateri) Penguins, possess feathered yellow or orange crests that protrude from the sides of the forehead (Jouventin 1982). A few research groups have recently initiated studies aimed at understanding the correlates and benefits of these striking colours. Massaro et al. (2003) showed in Yellow-eyed Penguins that the intensity of plumage and eye colouration reveals the parental quality of individuals. The expression of yellow-orange plumage in King Penguins is correlated with their current health and affects rates of pairing (Nolan et al. 2006; Jouventin et al. 2008). Earlier work by Jouventin (1982) indicated that Rockhopper and Macaroni Penguins that had their crests experimentally removed were less likely to secure a mate. Based on these studies, it is clear that in some penguin species bright colours have the potential to reveal mate quality and be the target of 
sexual selection. However, the precise axes along which these traits vary, including annually, sexually, environmentally and morphologically, remain largely unexplored in most species and will provide important baseline information for understanding how selection may shape the use of these traits.

Here, we chose to study one of the crested penguin species, the Snares Penguin, which is endemic to the Snares Islands $\left(48^{\circ} 02^{\prime} \mathrm{S}\right)$, a small island group (total area $328 \mathrm{ha}$ ) located $\sim 200 \mathrm{~km}$ south of the South Island of New Zealand. Nothing is known about the signalling variation or opportunities of colourful crests in these penguins, other than the unusual basis of their plumage colour production. In a recent string of biochemical studies, we have shown that all penguins develop their yellow feather colouration using a unique, fluorescent type of pigment that appears similar to the pterin pigments that various other birds, especially owls (Strigiformes) and blackbirds (Icteridae), use to colour their eyes yellow, orange and red (McGraw 2004; McGraw et al. 2004, 2007). Though we know qualitatively from this work that this pigment is the biochemical basis of yellow colouration in penguins, we have yet to conduct the quantitative investigation in any species to link pigment concentration with the colour characteristics of feathers (cf. for carotenoid- and melanin-based colours; Saks et al. 2003; McGraw et al. 2005) or with any correlates of individual quality.

Because both sexes in this species display conspicuous yellow colouration on exaggerated crests and use them in mutual trumpeting and vertical head-swinging displays between pair members (Warham 1974), they appeared from the outset to be likely candidates for visual signalling (for the role of colour in quality signalling in males and females of other bird species, also see Amundsen et al. 1997; Griggio et al. 2005). We measured the colour and pigment content of light-yellow crest-feathers from breeding male and female Snares Penguins and examined how they varied across years, between the sexes and in relation to morphometrics like body size and condition. We also studied how body size and condition varied among years, to test whether parallel interannual changes may occur for both crest-pigmentation and body condition. Our goal was to collect descriptive data on the 'information content' of these colours, that is what pieces of information they might reveal about an individual's quality if they, like in other penguins, serve as sexual or social signals to conspecifics.

\section{Methods}

\section{Field sampling}

Crest-feathers of Snares Penguins were collected from live birds breeding on the North East Island $\left(48^{\circ} 01^{\prime} \mathrm{S}, 166^{\circ} 36^{\prime} \mathrm{E}\right)$ of the Snares Island group in 2002 and 2003. We sampled 12 adult males and 11 adult females between 21 October and 8 November 2002, and seven adult males and 23 adult females between 13 October and 17 November 2003, with different birds studied in the two years. Laying occurs at the end of September and beginning of October, and parents incubate their eggs for 31-37 days before chicks hatch, usually at the beginning of November (Warham 1974). Thus, we sampled adult penguins when they were in their later stages of incubation and during their early chick-rearing phase (feathers were $\sim 6$ months old at time of sampling). Sex of adults was unequivocally determined by measuring depth and length of bills to the nearest $0.1 \mathrm{~mm}$ (Stonehouse 1971; Warham 1974; Massaro and Davis 2004). We also weighed birds to the nearest $100 \mathrm{~g}$ using a $10 \mathrm{~kg}$ Pesola spring balance. A single, randomly selected crest-feather was removed from each bird using scissors. Each feather was placed individually in a labelled, small, plastic zip-lock bag. All bags containing feathers were then immediately stored in a black, cardboard box to avoid bleaching by sunlight until feathers were analysed in the laboratory. We were unable to quantify length of the crest owing to practical difficulties with measurement and to research permit restrictions on whole feather removal.

\section{Crest colouration and pigmentation}

Following previous methods used for scoring the yellow-orange plumage colouration in King Penguins (Nolan et al. 2006) and many other birds (McGraw and Gregory 2004; McGraw and Nogare 2005; McGraw et al. 2006), we used a hand-held Colortron reflectance spectrophotometer (Light Source Inc., San Rafael, CA, USA) (Hill 1998) to determine hue, saturation and brightness of colourful feathers in the laboratory. This unit quantifies light visible to humans (400-700 nm) but not that visible to birds (including ultraviolet (UV) wavelengths). However, these feathers lacked a UV reflectance peak (Jouventin et al. 2005; McGraw et al. 2007) and thus this instrument is appropriate for colour measurement here. One feather per bird was laid against a standard white background and each was scored twice; repeatability for each colour measure was high (all $R_{\mathrm{i}}>0.7$, all $P<0.0001$ ), so we computed a mean score from the two measurements for use in statistical analyses.

After colour-scoring, feathers were ground for $10 \mathrm{~min}$ in a zirconia mixer mill (MM200, Retsch Inc., Haan, Germany) (McGraw et al. 2004) in the presence of $1 \mathrm{~mL} 0.5 \mathrm{M}$ aqueous $\mathrm{KOH}$. The slurry was removed and the jar rinsed with an additional $1 \mathrm{~mL}$ of base to recover any residual feather and pigment material. We centrifuged the mixture at $3000 \mathrm{rpm}$ for $5 \mathrm{~min}$ and transferred $1 \mathrm{~mL}$ of the clear supernatant to a quartz cuvette for determination of light absorbance (at $\lambda_{\max }=380 \mathrm{~nm}$ ) in a Beckman-Coulter ${ }^{\mathrm{TM}} \mathrm{DU}^{\circledR} 520$ absorbance spectrophotometer (Fullerton, CA). Because this pigment is unknown, we had no external standard with which we could determine true concentration; hence, concentration is reported in Absorbance Units per gram of feather. We are confident that this technique captures variation in pigment absorbance per se, and not absorbance by any other feather components (e.g. $\beta$-keratin oligopeptides), because these proteins absorb at very short wavelengths (<300 nm; e.g. Goldstein et al. 2004) and because our previous high-performance liquid chromatography study recovered feather pigments that absorb maximally in this UV-A range (McGraw et al. 2007).

\section{Statistical analyses}

Because colour and pigment concentration of the crest were normally distributed and had equal variances within each sex and year, we used parametric two-way analyses of variance (ANOVA) to investigate the effects of year and sex (and their interaction) on feather colouration (hue, saturation and 
brightness) and on pigment concentration. Because plumage saturation and brightness did not vary annually or sexually (see Results), we did not consider them in subsequent analyses. We used parametric Pearson's product-moment correlations to test for associations between crest-colour and pigment content within each sex and year.

We used two morphological measurements - length of bill and body mass - in our analyses, because these were the only two measures we had in both years and because they were strongly and positively correlated with our other measures of size (of the head, foot and flipper) from 2002 (all $r>0.4$ ). We then used the residuals from a regression of these two variables $\left(r^{2}=0.51, P<0.0001\right)$ to compute body condition (SchulteHostedde et al. 2005). All three of these morphological variables were also normally distributed and had equal variances, so we again used two-way ANOVA to examine effects of year, sex and year $\times$ sex interactions on length of bill, body mass and body condition. Finally, we used Pearson's product-moment correlations to test for relationships between crest-colour, pigment, body size and condition measures.

\section{Results}

\section{Sex and year differences in colour and pigment} content of crest-feathers

We found a significant effect of year on feather-hue (Table 1): birds in 2002 had crests with higher hue scores (more yellow) than did those in 2003 (Fig. 1). The interaction between sex and year was not statistically significant (Table 1). We found no significant effects of year, sex or their interaction on either plumage saturation or brightness (Table 1).

Pigment content of the crest varied nearly twofold among individuals within each sex, and for each sex showed significantly higher variation than both of our measures of body size (equality of variances $F$-tests, all $P<0.0001$ ). Mean crest pigment content also differed significantly by sex and year (Table 1). Female crests contained more yellow pigment than did those of males, and crests from 2002 were more heavily pigmented compared with those from 2003 (Fig. 1).

\section{Correlations between colour and pigment concentration of crest within sexes and years}

In both years, females with higher pigment concentrations in their crests developed significantly yellower crests (2002:

Table 1. Results from ANOVA investigating the effects of year, sex and their interaction on crest variables (colour and pigment content) in Snares Penguins

Degrees of freedom in all analyses $=1.49$; statistically significant effects are in bold

\begin{tabular}{lllll}
\hline Predictors & \multicolumn{4}{c}{ Crest response variables } \\
& Hue & Saturation & Brightness & Pigment content \\
\hline Sex & $F=2.33$ & $F=0.40$ & $F=1.72$ & $\boldsymbol{F}=\mathbf{8 . 0 3}$ \\
& $P=0.13$ & $P=0.53$ & $P=0.20$ & $\boldsymbol{P}=\mathbf{0 . 0 0 7}$ \\
Year & $\boldsymbol{F}=\mathbf{7 . 8 9}$ & $F=2.0$ & $F=1.52$ & $\boldsymbol{F}=\mathbf{3 3 . 8 9}$ \\
& $\boldsymbol{P}=\mathbf{0 . 0 0 7}$ & $P=0.16$ & $P=0.22$ & $\boldsymbol{P}<\mathbf{0 . 0 0 0 1}$ \\
Sex $\times$ year & $F=1.03$ & $F=0.06$ & $F=2.92$ & $F=2.12$ \\
& $P=0.32$ & $P=0.80$ & $P=0.10$ & $P=0.15$ \\
\hline
\end{tabular}

$r=0.86, n=11, P=0.0003 ; 2003: r=0.48, n=23, P=0.019$ ), but this was not the case in males (2002: $r=0.11, n=12, P=0.74$; 2003: $r=0.49, n=7, P=0.28$ ). Note that the relationship was stronger in 2002 than in 2003 for females, and was nearly equal in magnitude for males and females in 2003.

\section{Sex and year differences in body size and condition}

Interestingly, like colour and pigmentation of the crest, body condition varied significantly by year $\left(F_{1,54}=23.5, P<0.0001\right)$ : birds in 2002 were in much better condition than those in 2003 (Fig. 2). While there was no difference between sexes in condition $\left(F_{1,54}=0.08, \quad P=0.78\right)$, there was a significant year $\times \operatorname{sex}$ interaction $\left(F_{1,54}=20.8, P<0.0001\right)$; males were in significantly better condition in 2002 than in 2003, but females were not (Fig. 2). Body mass differed with respect to sex, year and the $\operatorname{sex} \times$ year interaction (all $F_{1,54}>22$, all $P<0.0001$ ). Males were heavier in 2002 than in 2003, and were heavier than females in 2002 but not 2003; females, in contrast, did not differ in mass between the two years (Fig. 2). Length of bill differed only by sex (Fig. 2; $F_{1,54}=55.2, P<0.0001$; for effects of year and year $\times$ sex interaction, both $F<1.0$ and $P>0.33$ ).
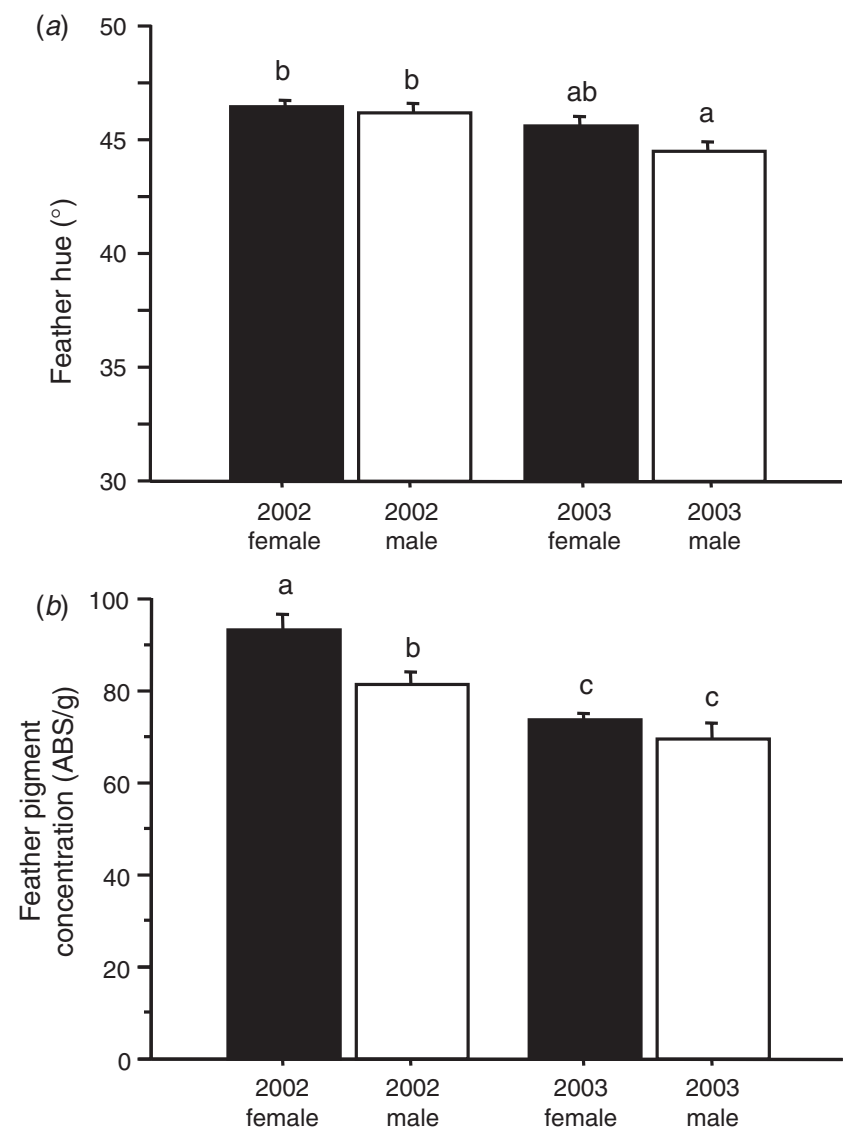

Fig. 1. Annual and sexual differences in (a) hue and (b) pigment concentration of crests in breeding Snares Penguins. Means + s.e. are shown. Shared letters above bars denote non-significant statistical differences. 

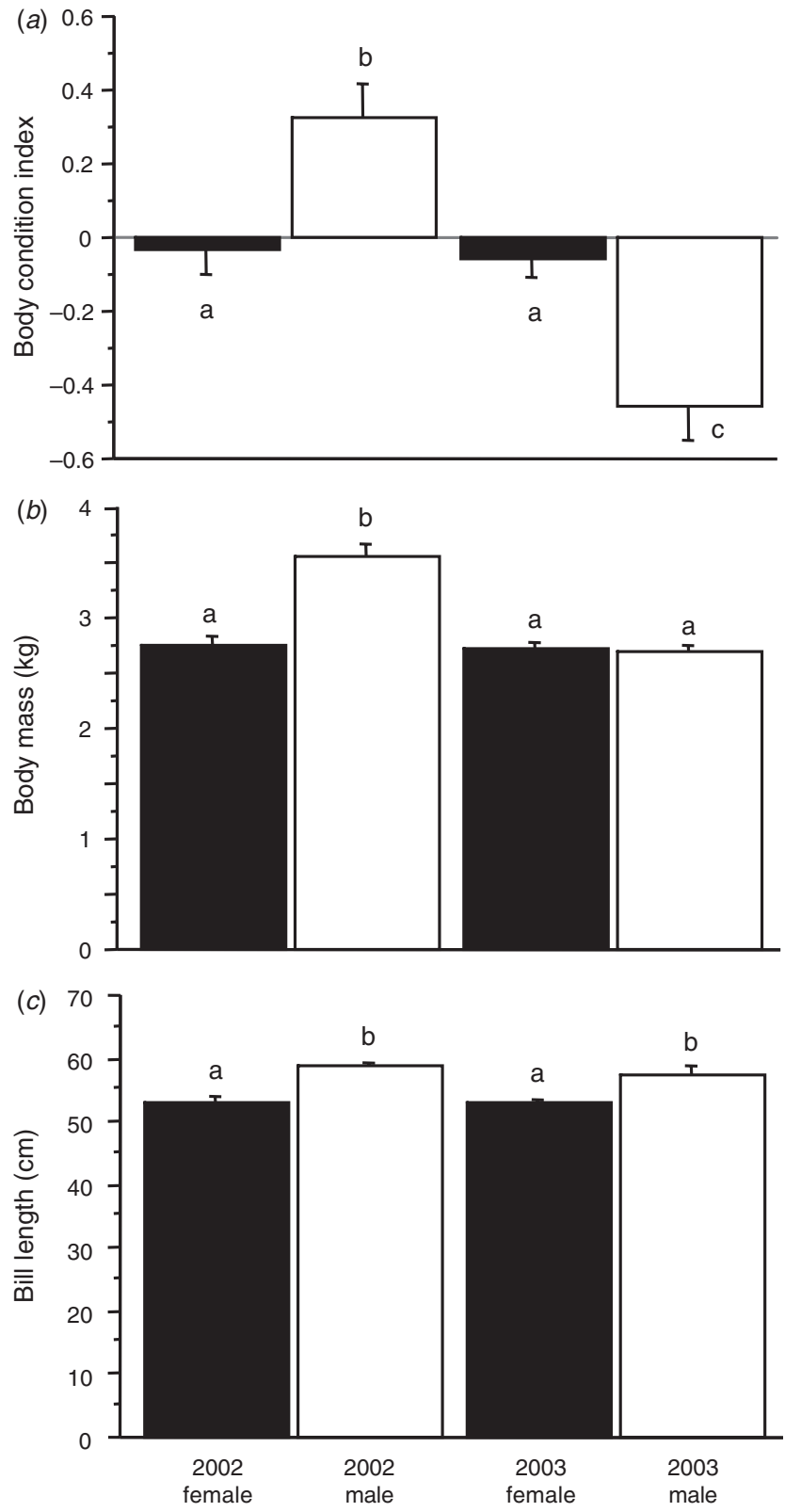

Fig. 2. Annual and sexual differences in ( $a$ ) body condition, $(b)$ body mass and $(c)$ length of bill in breeding Snares Penguins. See legend to Fig. 1 for further details of the bar charts.

\section{Relationships between crest pigmentation and body size and condition}

When we considered associations between body size and condition and crest colouration and pigment concentration separately in each sex and year, neither crest hue nor pigment content was significantly correlated with bill-length or body mass (all $P>0.1$ ). Only one comparison even approached statistical significance - the positive link between body mass and crest-hue in males from $2002(r=0.61, n=12, P=0.033)-$ but this did not hold after a sequential Bonferroni correction for multiple comparisons (for using each colour variable within each sex and year in three analyses; hence minimum $\alpha=0.017$ ). There was, however, one crest variable - male plumage hue in 2002 that was significantly and positively linked to body condition $(r=0.82, n=12, P=0.005)$.

\section{Discussion}

We examined annual, sexual and size- and condition-related variability in the colourful crests of male and female Snares Penguins. We found that crest pigmentation varied in relation to several biological parameters, which collectively make this feature a good candidate for visual signalling, beyond the fact that crests are conspicuous and used in mate-association displays. First, we detected sexual dimorphism in crest characteristics. Interestingly, it was females that had more pigmented crests than males, and females tended to have yellower crests than males as well, although this was not statistically significant. Increased female pigmentation is rare in birds (Amundsen 2000), and to our knowledge has never before been reported in penguins. Massaro et al. (2003) found no difference in colouration between the yellow post-ocular plumage stripe of male and female Yellow-eyed Penguins, but did find that males had more deeply pigmented eyes compared with females. Jouventin et al. (2008) has also demonstrated statistically significant sexual differences in plumage colouration (size of auricular patch) in King Penguins, though in this species too the sexes are visually indistinguishable to the human eye. The fact that the crests of female Snares Penguins contained more pigment than males suggests that any signalling pressure favouring this trait (mutual mate attraction, intrasexual dominance assertion, Kraaijeveld et al. 2007; e.g. Jones and Hunter 1999) is stronger in females. Had the crests not varied considerably in pigmentation within each sex, this trait would be a viable candidate as a sexual recognition signal (Dale 2006). However, based on the unusual and sex-specific breeding investments of this species of crested penguin, it is conceivable that males may be the more choosy (and hence females the more ornamented) sex. Unlike other penguins, male Eudyptes penguins are wholly responsible for brooding the chick during the guarding phase (Warham 1974), which is likely to be an adaptation to protect offspring from rival males that can cause loss of progeny (M. Massaro et al., unpubl. data). This scenario approaches the reversed sex-role mating systems of some shorebird species, where male effort and defence controls female breeding opportunities (Ligon 1999).

Second, we found interannual differences in colour expression of the crest. In both sexes, yellow crests were more colourful and heavily pigmented in 2002 than in 2003. Prior studies of carotenoid- (Linville and Breitwisch 1997) and melanin-based (Otter and Ratcliffe 1999) plumage colouration in birds have used across-year differences in colouration to infer that it is under environmental control (e.g. diet, health, parasites). For example, Northern Cardinals (Cardinalis cardinalis) grew less red plumage in the year after which a deep winter cold spell dramatically reduced fruit availability (Linville and Breitwisch 1997). However, in these cases, data have not been available to examine changes in the condition of the birds for which the annual colour change was observed. We did this in our study population of Snares Penguins and found that, in the same year 
that crests were more pigmented, birds were in better condition. Though not providing robust support (like an experimental manipulation might; also see more below), this observation is consistent with condition-dependent expression of plumage colouration based on yellow-pigments in penguins. Though we cannot say whether an individual's condition at the time of feather moult affects its colour production, our results reveal a colourcondition association during the mating period, when the visual signal could be used.

At present, we cannot state explicitly what environmental or physiological variable or variables (e.g. diet, health, hormones) may be linked to or responsible for such a change. We are not even sure whether these yellow feather-pigments are diet-derived (i.e. Snares Penguins consume krill, squid and fish, which can possess yellow pterins as skin colourants; Le Guyader and Jesuthasan 2002) or if they are synthesised endogenously (from nitrogenous base precursors; McGraw et al. 2007) in colourful penguins. Regardless, it is useful to point out that pterin pigments can serve as potent antioxidants (McGraw 2005), so no matter the method of acquisition these pigments may be inexorably linked to, and hence an excellent signal of, an individual's health and condition (Nolan et al. 2006). Moreover, even in this 2-year study, it is noteworthy that there were annual differences in oceanic primary productivity in the quadrant $45^{\circ}-50^{\circ} \mathrm{S} 165^{\circ}-170^{\circ} \mathrm{E}$, where breeding Snares Penguins forage (Mattern 2006). In February, when Snares Penguins replenish body resources in preparation for their annual moult (Warham 1974), mean concentrations of chlorophyll $a$ (chl $a$ ) were higher in 2002 than in $2003\left(0.507 \mathrm{mg} \mathrm{m}^{-3} v\right.$. $0.454 \mathrm{mg} \mathrm{m}^{-3}$; from SeaWiFS Level 3 global ocean colour data, http://oceancolor.gsfc.nasa.gov, accessed 30 April 2006). $\mathrm{Chl} a$ concentration is a measure of phytoplankton biomass, which is utilised by grazing zooplankton species, such that higher chl $a$ concentrations can be indicative of enhanced feeding conditions for planktivorous species like Snares Penguins (Bradford-Grieve et al. 2003). Therefore, lower chl $a$ concentrations in 2003 suggest that pre-moult feeding conditions that year were not as good as in 2002; consistent with this, we found that body condition and crest-pigmentation were lower in 2003 than in 2002.

Third, we found some correlational links between the body size and condition of individuals and characteristics of their crests. These analyses admittedly are the weakest in our paper, owing to small sample sizes and the statistical (Bonferroni) corrections we have applied for running multiple comparisons. However, following the suggestions of Montgomerie (2006), we remind readers that this is an exploratory study and that it is worth noting the several marginally significant results that we have uncovered here. Correlations were consistently positive between morphological variables and crest-hue, approached statistical significance in some cases (data not shown), and in one instance (for males in 2002) we detected positive and significant condition-dependence of expression of plumage hue. Although one may strictly view the lack of abundant and significant correlations in our paper as evidence against condition-dependence of these features, we feel that, if all of our results are taken together, and in light of other recent evidence that plumage colour is condition-dependent in King Penguins (Nolan et al. 2006; Dobson et al. 2008), these findings provide exciting baseline information for future tests of the hypothesis that yellow colouration in Snares and other penguins is conditiondependent. Additional studies should employ a suite of condition measures and should quantify other attributes of 'quality' (e.g. aggressiveness, hormone titers, genetic make-up) as well as selection gradients to more comprehensively assess the signalling role and information of yellow colouration. Moreover, as of yet, no experimental manipulations have been conducted in penguins to better understand whether diet, parasites or other environmental stressors (temperature, storms, etc.) influence colouration of head plumage or bare parts, such as bill, eyes and feet. While crested penguins may appear to be good model species for this line of work (e.g. they breed in large colonies, they are readily observed and their crestfeathers are easily manipulated or removed for laboratory analyses, or both), access to their subantarctic island breeding sites is restricted and in New Zealand these islands, including their flora and fauna, are protected by the Department of Conservation. Hence, it might be more feasible to conduct initial experimental work on the condition dependence of penguin colours in zoo populations rather than in the wild.

It was unusual that lines of evidence for conditiondependence of characteristics of crests were not consistent between the sexes. Annual differences were observed for crest-colour in both sexes, but correlations between colour and condition within sexes were strongest in males. This discrepancy may be explained at least in part by the dual mechanisms by which yellow plumage colour is created; yellow pigments are deposited in a matrix of white, reflective, keratinised tissue, leaving the possibility for two sources of colour variation - pigment concentration and keratin microstructure and reflectivity (Shawkey and Hill 2005). In females, we found that plumage hue was explained significantly by pigment concentration (which also varied between years) but this was not true in males, which have less pigment in their crests. It seems that comparatively more of the colour of feathers of a male may be explained by white feather microstructure, and perhaps it was variation in this axis of colour production that showed sensitivity to condition. Production of white structural colour can be conditiondependent in birds (Gustafsson et al. 1995; Torok et al. 2003), though not in all species or situations (e.g. Shawkey et al. 2006). In future work, it is clear that more attention should be paid to these two methods of colour generation for pigmentrich ornaments in animals, especially in such lightly pigmented tissues like the crests of these penguins.

\section{Acknowledgements}

This study was approved by the New Zealand (NZ) Department of Conservation and the University of Otago Animal Ethics Committee and complies with the current laws of NZ. In particular, we thank the Southland Conservancy from the Department of Conservation for support and permits. We are grateful to L. Davis, who helped with obtaining working permits. We also thank D. Houston, U. Ellenberg, and A. Setiawan for help in the field; M. Toomey for input on analyses of feather pigment; and R. Phillips, K. Buchanan, F. S. Dobson and four anonymous referees for helpful comments on the manuscript. Field trips to the Snares Islands were financially supported by the Yellow-eyed Penguin Trust and the University of Otago. During manuscript preparation, funding was provided 
to KJM and TJR by the School of Life Sciences and College of Liberal Arts and Sciences at Arizona State University and to MM by the New Zealand Foundation for Research, Science, and Technology.

\section{References}

Amundsen, T. (2000). Why are female birds ornamented? Trends in Ecology \& Evolution 15, 149-155. doi: 10.1016/S0169-5347(99)01800-5

Amundsen, T., Forsgren, E., and Hansen, L. T. T. (1997). On the function of female ornaments: male bluethroats prefer colourful females. Proceedings of the Royal Society of London. Series B: Biological Sciences 264, 1579-1586. doi: 10.1098/rspb.1997.0220

Andersson, M. (1994). 'Sexual Selection.' (Princeton University Press: Princeton, NJ.)

Bradford-Grieve, J. M., Probert, P. K., Nodder, S. N., Thompson, D., Hall, J., Hanchet, S., Boyd, P.,Zeldis, J., Baker, A. N., Best, H. A., Broekhuizen, N., Childerhouse, S., Clark, M., Hadfield, M., Safi, K., and Wilkinson, I. (2003). Pilot trophic model for subantarctic water over the Southern Plateau, New Zealand: a low biomass, high transfer efficiency system. Journal of Experimental Marine Biology and Ecology 289, 223-262. doi: 10.1016/S0022-0981(03)00045-5

Dale, J. (2006). Intraspecific variation in coloration, In 'Bird Coloration. Vol. II. Function and Evolution'. (Eds G. E. Hill and K. J. McGraw.) pp. 36-86. (Harvard University Press: Cambridge, MA.)

Dobson, F. S., Nolan, P. M., Nicolaus, M., Bajzak, C., Coquel, A. S., and Jouventin, P. (2008). Comparison of color and body condition between early and late breeding king penguins. Ethology 114, 925-933. doi: $10.1111 / \mathrm{j} .1439-0310.2008 .01545 . x$

Goldstein, G., Flory, K. R., Browne, B. A., Majid, S., Ichida, J. M., and Burtt, E. H. Jr (2004). Bacterial degradation of black and white feathers. Auk 121, 656-659. doi: 10.1642/0004-8038(2004)121 [0656:BDOBAW]2.0.CO;2

Griggio, M., Valera, F., Casas, A., and Pilastro, A. (2005). Males prefer ornamented females: a field experiment of male choice in the rock sparrow. Animal Behaviour 69, 1243-1250. doi: 10.1016/j.anbehav. 2004.10.004

Gustafsson, L., Qvarnstrom, A., and Sheldon, B. C. (1995). Trade-offs between life-history traits and a secondary sexual character in male collared flycatchers. Nature 375, 311-313. doi: 10.1038/375311a0

Hill, G. E. (1998). An easy, inexpensive means to quantify plumage coloration. Journal of Field Ornithology 69, 353-363.

Hill, G. E., and McGraw, K. J. (2006a). 'Bird Coloration. Vol. I. Mechanisms and Measurements.' (Harvard University Press: Cambridge, MA.)

Hill, G. E., and McGraw, K. J. (2006b). 'Bird Coloration. Vol. II. Function and Evolution.' (Harvard University Press: Cambridge, MA.)

Jones, I. L., and Hunter, F. M. (1999). Experimental evidence for mutual inter- and intrasexual selection favouring a crested auklet ornament. Animal Behaviour 57, 521-528. doi: 10.1006/anbe.1998.1012

Jouventin, P. (1982). 'Visual and Vocal Signals in Penguins, Their Evolution and Adaptive Characters.' (Paul Parey: Berlin.)

Jouventin, P., Nolan, P. M., Ornborg, J., and Dobson, F. S. (2005). Ultraviolet beak spots in King and Emperor Penguins. Condor 107, 144-150. doi: $10.1650 / 7512$

Jouventin, P., Nolan, P. M., Dobson, F. S., and Nicolaus, M. (2008). Colored patches influence pairing rate in King Penguins. Ibis 150, 193-196.

Kraaijeveld, K., Kraaijeveld-Smit, F. J. L., and Komdeur, J. (2007). The evolution of mutual ornamentation. Animal Behaviour 74, 657-677. doi: 10.1016/j.anbehav.2006.12.027

Le Guyader, S., and Jesuthasan, S. (2002). Analysis of xanthophore and pterinosome biogenesis in zebrafish using methylene blue and pteridine autofluorescence. Pigment Cell Research 15, 27-31. doi: 10.1034/j.16000749.2002.00045.x
Ligon, J. D. (1999). 'The Evolution of Avian Breeding Systems.' (Oxford University Press: Oxford, UK.)

Linville, S. U., and Breitwisch, R. (1997). Carotenoid availability and plumage coloration in a wild population of northern cardinals. Auk 114, 796-800.

Masello, J. F., and Quillfeldt, P. (2003). Body size, body condition and ornamental feathers of Burrowing Parrots: variation between years and sexes, assortative mating and influences on breeding success. Ети 103, 149-161. doi: 10.1071/MU02036

Massaro, M., and Davis, L. S. (2004). Preferential incubation positions for different sized eggs and their influence on incubation period and hatching asynchrony in Snares crested (Eudyptes robustus) and yelloweyed penguins (Megadyptes antipodes). Behavioral Ecology and Sociobiology 56, 426-434. doi: 10.1007/s00265-004-0803-8

Massaro, M., Davis, L. S., and Darby, J. T. (2003). Carotenoid-derived ornaments reflect parental quality in male and female yellow-eyed penguins (Megadyptes antipodes). Behavioral Ecology and Sociobiology 55, 169-175. doi: 10.1007/s00265-003-0683-3

Mattern, T. (2006). Marine ecology of offshore and inshore foraging penguins: the Snares penguin Eudyptes robustus and Yellow-eyed penguin Megadyptes antipodes. Ph.D. Thesis, University of Otago, Dunedin, New Zealand.

McGraw, K. J. (2004). Not all red, orange, and yellow animal colors are carotenoid-based: the need to couple biochemical and behavioral studies of color signals. Proceedings of the Indian National Science Academy B 70, 593-598.

McGraw, K. J. (2005). The antioxidant function of many animal pigments: are there consistent health benefits of sexually selected colorants? Animal Behaviour 69, 757-764. doi: 10.1016/j.anbehav.2004.06.022

McGraw, K. J., and Gregory, A. J. (2004). Carotenoid pigments in male American goldfinches: what is the optimal biochemical strategy for becoming colourful? Biological Journal of the Linnean Society 83, 273-280. doi: 10.1111/j.1095-8312.2004.00388.x

McGraw, K. J., and Nogare, M. C. (2005). Distribution of unique red feather pigments in parrots. Biology Letters 1, 38-43. doi: 10.1098/ rsbl.2004.0269

McGraw, K. J., Wakamatsu, K., Ito, S., Nolan, P. M., Jouventin, P., Dobson, F. S., Austic, R. E., Safran, R. J., Siefferman, L. M., Hill, G. E., and Parker, R. S. (2004). You can't judge a pigment by its color: carotenoid and melanin content of yellow and brown feathers in swallows, bluebirds, penguins, and domestic chickens. Condor 106, 390-395. doi: 10.1650/7384

McGraw, K. J., Safran, R. J., and Wakamatsu, K. (2005). How feather colour reflects its melanin content. Functional Ecology 19, 816-821. doi: 10.1111/j.1365-2435.2005.01032.x

McGraw, K. J., Nolan, P. M., and Crino, O. L. (2006). Carotenoid accumulation strategies for becoming a colorful house finch: analyses of plasma and liver pigments in wild molting birds. Functional Ecology 20, 678-688. doi: 10.1111/j.1365-2435.2006.01121.x

McGraw, K. J., Toomey, M. B., Nolan, P. M., Morehouse, N. I., Massaro, M., and Jouventin, P. (2007). A description of unique fluorescent yellow pigments in penguin feathers. Pigment Cell Research 20, 301-304. doi: $10.1111 /$ j.1600-0749.2007.00386.x

Montgomerie, R. (2006). Analyzing colors. In 'Bird Coloration. Vol. I. Mechanisms and Measurements.' (Eds G. E. Hill and K. J. McGraw.) pp. 90-147. (Harvard University Press: Cambridge, MA.)

Nolan, P. M., Dobson, F. S., Dresp, B., and Jouventin, P. (2006). Immunocompetence is signaled by ornamental colour in king penguins, Aptenodytes patagonicus. Evolutionary Ecology Research 8, 1325-1332.

O'Donald, P. (1980). Sexual selection by female choice in a monogamous bird: Darwin's theory corroborated. Heredity 45, 201-217. doi: 10.1038/ hdy. 1980.61 
Otter, K., and Ratcliffe, L. (1999). Relationship of bib size to age and sex in the black-capped chickadee. Journal of Field Ornithology 70, 567-577.

Parker, T. H., and Ligon, J. D. (2003). Female mating preferences in red junglefowl: a meta-analysis. Ethology Ecology and Evolution 15, 63-72.

Saks, L., McGraw, K. J., and Horak, P. (2003). How feather colour reflects its carotenoid content. Functional Ecology 17, 555-561. doi: 10.1046/j.1365-2435.2003.00765.x

Schulte-Hostedde, A. I., Zinner, B., Millar, J. S., and Hickling, G. J. (2005). Restitution of mass-size residuals: validating body condition indices. Ecology 86, 155-163. doi: 10.1890/04-0232

Shawkey, M. D., and Hill, G. E. (2005). Carotenoids need structural colours to shine. Biology Letters 1, 121-124. doi: 10.1098/rsbl.2004.0289

Shawkey, M. D., Hill, G. E., McGraw, K. J., Hood, W. R., and Huggins, K. (2006). An experimental test of the contributions and condition dependence of microstructure and carotenoids in yellow plumage coloration. Proceedings of the Royal Society of London. Series B: Biological Sciences 273, 2985-2991. doi: 10.1098/rspb.2006.3675
Stonehouse, B. (1971). The Snares Islands penguin Eudyptes robustus. Ibis 113, 1-7. doi: 10.1111/j.1474-919X.1971.tb05118.x

Torok, J., Hegyi, G., and Garamszegi, L. (2003). Depigmented wing patch size is a condition-dependent indicator of viability in male collared flycatchers. Behavioral Ecology 14, 382-388. doi: 10.1093/beheco/ 14.3.382

Warham, J. (1974). The breeding biology and behaviour of the Snares crested penguin. Journal of the Royal Society of New Zealand 4, 63-108.

Manuscript received 11 July 2008, accepted 8 December 2008 